\title{
DIGESTÃO SIMULADA DE FORMULAÇÕES DE BEBIDA ESPORTIVAS CONTENDO DIFERENTES PROBIÓTICOS
}

\author{
*Luciana C. Fino, Fabíola L. Pena, Thais R. Silva, Vivian C. C. Rodrigues, Luiz G. S. Silva, Adriane E. C. Antunes.
}

\section{Resumo}

O leite fermentado é um alimento com alegação funcional devido à presença de probióticos em sua composição, trazendo diversos benefícios a seus consumidores regulares. Assim, o presente trabalho buscou avaliar a viabilidade de diferentes probióticos frente ao processo de digestão simulada in vitro. Os resultados demonstraram que o lactobacillus casei cepa BGP93 apresentou melhor sobrevivência ao ensaio in vitro quando comparado aos outros probióticos (LA3 e SP1), mas todos sofreram decréscimo de suas contagens iniciais.

\section{Palavras-chave:}

leite fermentado, probióticos, viabilidade.

\section{Introdução}

Os probióticos estão presentes em diversos produtos da indústria de alimentos, já que alguns alimentos são veículos ideais para a distribuição e chegada desses microrganismos ao trato gastrointestinal humano, graças ao seu efeito protetor sobre cepas probióticas durante sua passagem até o local de ação principal, o intestino. As bebidas lácteas fermentadas são um exemplo desses produtos, pois representam boa matriz na qual os probióticos podem sobreviver bem e ser adequadamente aportados para os consumidores. Porém, para que os benefícios se tornem efetivos, é necessário que esses microrganismos estejam em quantidade mínima viável no produto até o final de seu prazo de validade e que resistam adequadamente ao processo de digestão.

O objetivo desse trabalho foi avaliar a sobrevivência de diferentes probióticos frente ao processo de digestão simulada.

\section{Resultados e Discussão}

As culturas avaliadas no projeto foram: BGP93, SP1 e LA3 (Lactobacillus casei, L. rhamnosus e L. acidophilus) com contagens iniciais, isto é, sem digestão, igual a 8,$29 ; 9,26 ; 5,70 \log \mathrm{UFC} / \mathrm{mL}$ respectivamente.

$O$ ensaio de digestão consiste em três fases: gástrica, com adição de ácido clorídrico e solução de pepsina $(0,3 \mathrm{~g} / \mathrm{L})$ e lipase $0,9 \mathrm{mg} / \mathrm{L})$, mantendo o $\mathrm{pH}$ entre 2 - 2,5 ; entérica l, com adição de solução tampão fosfato de sódio, bile (10g/L) e pancreatina (1g/L), mantendo $\mathrm{pH}$ entre 4,5 - 5,5; entérica II, com nova adição de solução fosfato de sódio, bile e pancreatina à amostra, com a mesma concentração das enzimas, mantendo $\circ \mathrm{pH}$ entre 6,5 - 7,5. As amostras foram submetidas a um banho metabólico do tipo Dubnoff a $37^{\circ} \mathrm{C}$, e constante agitação a 150 RPM durante seis horas. Ao término de cada fase fez-se análises de viabilidade dos probióticos, inoculando $10 \mu \mathrm{L}$ das diluições decimais em placas de petri com MRS Agar acidificado ( $\mathrm{pH} 5,2$ ), com plaqueamento drop plate e incubação em anaerobiose por $72 \pm 2$ horas a $37^{\circ} \mathrm{C}$.

Para analisar os resultados utilizou-se a Taxa de Sobrevivência de Probióticos, com a seguinte fórmula: $\mathrm{TS}=\mathrm{CMDD} / \mathrm{CMSD}^{*} 100$, onde TS é a taxa de sobrevivência, CMDD é a contagem de microrganismos durante a digestão (para cada fase) e CMSD é a contagem dos microrganismos sem digestão.

Os resultados da viabilidade dos probióticos apresentados na Figura 1 mostram que houve uma diminuição expressiva da contagem de Unidades Formadoras de Colônia (UFC) dos mesmos desde a fase gástrica até a entérica II, já que as soluções de enzimas e a agitação constante desempenham papel extremamente agressivo a essas bactérias. Entretanto, parte dos probióticos sobreviveram, e quando estes encontraram $0 \mathrm{pH}$ mais próximo da neutralidade conseguiram se estabilizar e se recuperar dos danos causados nas fases anteriores. Todas as culturas apresentaram decréscimo de suas contagens iniciais, mas o que deve-se levar em conta é a funcionalidade do probiótico e não simplesmente o número final de suas colônias.

Figura 1 - Taxa de sobrevivência dos probióticos (\%)

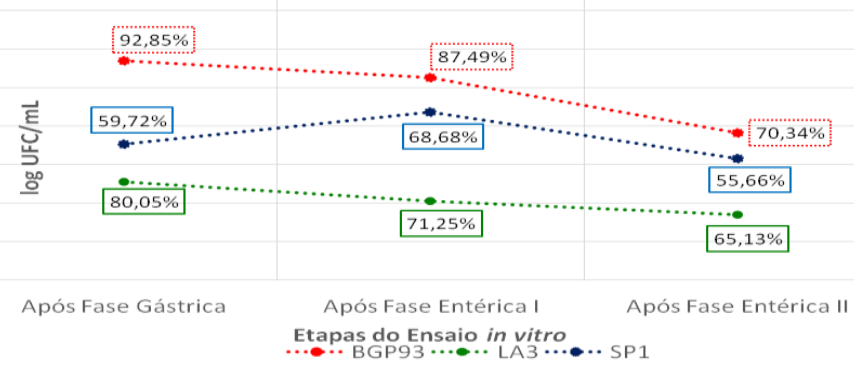

\section{Conclusões}

O lactobacillus casei cepa BGP93 apresentou maior taxa de sobrevivência ao final da digestão simulada quando comparado aos outros probióticos, entretanto todos sofreram um decréscimo de suas contagens iniciais.

[1] ANTUNES, A. E. C. et al. Probióticos: agentes promotores de saúde. Rev. Soc. Br Al. Nut. 2007:32(3):113-132.

[2] BRASIL, 2001. Agência Nacional de Vigilância Sanitária. Resolução - RDC No 12, de 2 de janeiro de 2001.

[3] BURITI, F. C. A.; CASTRO, I. A.; SAAD, S. M .I. Viability of Lactobacillus acidophilus in synbiotic guava mousses and its survival under in vitro simulated gastrointestinal conditions. International Journal of Food Microbiology 137, 121-129, 2010.

[4] REDONDO NC. Avaliação in vitro de características probióticas do Enterococcus faecium CRL183 e do Lactobacillus helveticus ssp. jugurti 416. Araraquara. Dissertação [Mestrado em Alimentos e Nutrição] - Faculdade de Ciências Farmacêuticas da UNESP; 2008. 